\title{
岷江上游河岸带土地覆盖格局及其生态学解释
}

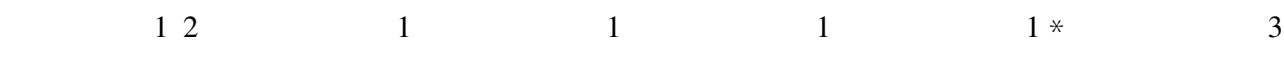

(1 北京师范大学生命科学学院, 北京 100875) (2 云南大学生态学与地植物学研究所, 昆明 650091)

(3 中国科学院植物研究所植物生态学研究中心 北京 100093)

摘 要 针对峮江上游干流河岸带的土地覆盖状况, 将该区沿河流主干分为 68 个样方，结合空间信息及环境因 子对这些样方及流域内的 12 种土地覆盖类型, 采用双向指示种分析法 (Two-way indicator species analysis, TWINSPAN)和除趋势典范对应分析法 (Detrended canonical correspondence analysis, DCCA)对种类和样方进行分类和排 序, 以揭示其生态学意义及环境影响因素。结果显示: 1) 研究区土地覆盖可分为高植被覆盖、中度植被覆盖和低/ 非植被覆盖 3 种类别, 各类别在流域不同位置分布状况不同, 整个流域以中度植被覆盖为主。2) 所取样方可分为 8 个类群, 各自拥有相似的土地覆盖组成, 呈聚集分布。3)根据土地覆盖特征, 河岸带可分为上、中、下 3 段, 流域上 段河岸带植被覆盖度较高; 中段以中度植被覆盖类型为主, 占总面积最大;下段集中了大部分人工地覆盖类型。 4) 气温、海拔是影响峎江上游干流河岸带土地覆盖格局的最重要因素, 此外降水和人类活动对其也有影响。除干 旱河谷区外，顺流自上而下，海拔逐渐降低，水热条件逐渐改善，同时人类干扰强度也逐渐增加，是造成流域 3 段截 然不同的土地覆盖格局的原因。5)干旱河谷特殊的土地覆盖格局是水、热共同作用造成的。总之,岷江上游河岸 带土地覆盖呈现出一定的梯度变化特征,自然条件的制约是形成这一格局的主要原因。

关键词 河岸带 TWINSPAN DCCA 土地覆盖 峮江上游

\section{INTERPRETING ECOLOGICAL LAND COVER PATTERN FOR THE RIPARIAN ZONE OF THE UPPER MINJIANG RIVER , CHINA}

\author{
ZHOU Rui ${ }^{1}{ }^{2}$, HU Yu-Zhe ${ }^{1}$, XIONG Ying ${ }^{1}$, WANG Hui ${ }^{1}$, GE Jian-Ping ${ }^{*}{ }^{*}$, and BI Xiao-Li ${ }^{3}$ \\ ${ }^{1}$ Ministry of Education Key Laboratory for Biodiversity Science and Engineering , College of Life Sciences , Beijing Normal University , Beijing 100875 , \\ China , ${ }^{2}$ Institute of Ecology and Geobotany , Yunnan University , Kunming 650091, China , and ${ }^{3}$ Research Center of Plant Ecology \& Conservation \\ Biology , Institute of Botany, Chinese Academy of Sciences , Beijing 100093 , China
}

\begin{abstract}
Aims Riparian zones encompass sharp environmental gradients with an unusually diverse array of landforms, habitats and communities. The land cover pattern of the riparian zone was studied in the upper Minjiang River, China, to determine :1) the land cover pattern and 2) environmental factors affecting the pattern.

Methods Sixty-eight quadrats with 12 classes of land cover were sampled along the main stream of the river. Based on the spatial information and environmental factors, the pattern of land cover was investigated using two-way indicator species analysis (TWINSPAN) and detrended canonical correspondence analysis (DCCA).

Important findings Land cover was classified into high , moderate and low/non-vegetation types. These had different distributions, with the moderate type most predominant. The quadrats were classified into 8 groups , within which each quadrat had similar land cover. Based on land cover , the riparian zone could be divided into three parts : the upper part with mostly high vegetation types, the middle part, which occupied the greatest area , mostly with moderate vegetation types, and the lower part, mostly with the man-made land cover type. Temperature and elevation were the most important environmental factors related to the land cover pattern , followed by precipitation and human distribution. From upper to lower parts of the riparian zone, temperature , precipitation and human activity increase. The overall result is explicitly different land cover patterns in the three parts of the riparian zone. The pattern of dry valley is controlled by the interaction of water and temperature. Ordination was useful in interpreting the land cover pattern of the riparian zone in the upper Minjiang River. Environment factors had a larger effect on this pattern than human factors.
\end{abstract}

Key words riparian zone, TWINSPAN , DCCA , land cover , the upper Minjiang River 
河岸带 (Riparian zone) 是流域景观中一个重要 元素, 它是陆地生态系统与水体生态系统连接的纽 带, 同时与河流系统一起构成连接整个流域上下游 的廊道。它既可能是流域生态系统中物质、能量、信 息的传输和交换通道，又可能成为其屏障(陈吉泉， 1996 ; Naiman \& Decamps，1997; 邓红兵等，1998)。 河岸带伴随着河流连续统 (River continuum) (Vannote et al. , 1980) ,由源头集水区起，以下经各级河流流 域, 呈不规则的线性连接, 下游河岸带的生态系统过 程同上游直接相关, 环境变量逐步变化, 人类干扰强 度也渐次改变, 形成相应的植被功能组类型以及土 地覆盖类型梯度变化 (Corbacho et al ., 2003 ; Lyon \& Sagers，2003），成为一个连续、独特而完整的系统。 从景观生态学的视点来看, 河岸带为整个大的景观 提供了一组独特而多样的地形、生境和群落 (Schwabe , 1989 ; Malanson, 1993)。由于其结构、功 能上的特殊性, 它已成为生物多样性保护 (Elderd, 2003 ;Fleishman et al., 2003 ; Medina-Vogel et al. , 2003 ) 以及流域生态水文功能实现 (Tabacchi \& Planty-Tabacchi，2003; Yeakley et al. ,2003)的热点区域， 与此同时, 河岸带植被作为河岸景观基质极易受到 人类活动的影响 (Heartsill-Scalley \& Aide, 2003; Lamb et al ., 2003 ; Aguiar \& Ferreira，2005）,日益成 为流域管理的重点区域。

岷江上游地处北半球中纬度内陆, 四川盆地和 青藏高原的过渡地带, 由于地理位置特殊, 地形地貌 类型复杂多样, 生物多样性丰富, 孕育了其脆弱而复 杂多样的生态系统类型。它既是长江上游生态屏障 的重要组成部分, 也是成都平原的重要生态屏障和 水源的生命线。沿江而下, 在地形地貌、气候条件及 人类活动强度影响下, 河岸带景观各异, 尤以干旱、 半干旱河谷为其生态最脆弱地区。干流 $3000 \mathrm{~m}$ 范 围内的河岸带也是岷江上游农田的集中分布区(刘) 丽娟，2004)。近几年来已对岷江上游土地覆盖格 局有了很多研究 (Zhao et al. , 2005; 李爱农等, 2005 ; 李崇巍等，2005），却鲜见针对河岸带的分析。

对河岸带进行土地覆盖分析时,重点应放在其 伴随流域系统发生的一系列梯度变化及其环境影响 因素, 加之河岸带独特的线型结构, 使其与传统景观 格局研究范式有很大差别。而河岸带类似于植被研 究中的样带 或可借用植被数量分析中的分类、排序 等方法。这类方法广泛用于植被生态学研究, 能够 合理、有效地解释植物种和植物群落的空间分布与 环境因子之间的关系(张峰和张金屯, 2000 ; 宋永
昌，2001; 张金屯，2004）。通常用于景观分析的土 地覆盖数据即已是对地表特征的一种划分, 然而这 种分类仅是基于地表土地覆盖特征或是地表反射率 进行的, 并不能直接揭示出各种类型之间以及各类 型与环境因子的内在联系, 而植被分类方法却可以 揭示出其生态关系。植被排序是从植被梯度分析发 展而来的, 能使排序轴反映一定的生态梯度, 解释研 究对象分布与环境因子间的关系。

从数学上讲,这些方法是施于原始数据集合的 一套处理规则，至于这些规则该不该用于所分析的 对象及分析结果的解释, 则独立于方法本身而依赖 于相关专业知识, 即凡是以研究实体和属性相互关 系为目的的学科均可使用这些方法 (张金屯, 2004)。但这些在植被群落水平上发展起来的方法， 能否移植到景观水平分析土地覆盖格局; 在空间尺 度及研究对象都发生了重大变化的情况下, 它们是 否仍然能够成功揭示生态学意义, 是值得探讨的问 题，也是对土地覆盖及景观格局定量方法的一种尝 试。

\section{1 研究对象及方法}

\section{1 研究区域及数据来源}

岷江, 是长江上游的重要支流之一, 就水量而 言, 是长江上游最大的支流。都江堰以上为其上游, 地处横断山区东缘, 川西北地区, 位于 $31^{\circ} \sim 33^{\circ} \mathrm{N}$, $102^{\circ} \sim 104^{\circ} \mathrm{E}$ 之间。河流全长 $340 \mathrm{~km}$ 落差达 3009 $\mathrm{m}$, 河谷深切, 河道平均比降 $8.35 \%$ ，流域面积 2.29 $\mathrm{km} \times 104 \mathrm{~km}$,总人口约 38 万, 其行政大部分隶属于 四川省阿坝藏族美族自治州,少部分隶属于都江堰 市(郭敬辉等, 1985)。岷江上游在植被分布上处于 中国东南湿润森林区向西北半干旱草原过渡地带。

沿干流河岸带自北向南,土地覆盖类型与所处 的复杂自然条件相适应, 呈现多样而独特的分布格 局。其中茂县沟口以下至汶川附近的干流为半干旱 偏湿干旱河谷, 长度为 $108 \mathrm{~km}$, 面积 $110 \mathrm{~km}^{2}$, 幅度 200 300 m(张荣祖, 1992)。自然因素的变化, 也影 响到人口及居民区的分布状况，顺江而下，河岸带人 口逐渐增多，城镇用地渐次加大。

本文所用土地覆盖类型图由中国科学院地理科 学与资源研究所提供, 并依据中国资源环境数据库 标准进行数据编码。地形以及居民点数据来自国家 基础地理信息中心提供的全国 $1: 25$ 万全要素地理 数据库。降水量依据四川省水文水资源局提供的 $1988 \sim 2000$ 年降水量资料, 采用反距离权重插值 
(Inverse distance weighting, IDW) 方法对岷江流域上 游及周边地区的雨量站共计 51 个数据点进行空间 插值，从而获得累年年平均降水量(以下简称年降水 量) 空间分布图1)。气温数据由国家气象中心提供， 包括 41 个四川省国家标准气象台站的累年各月平 均气温 时间序列为 1971 2000 年, 采用 MTCLIM 算 法(刘丽娟等，2005)，经 Kriging 插值获得累年年平 均温度 (以下简称年均温) 空间分布图 (刘丽娟, 2004)。

\section{2 研究方法}

运用 $\mathrm{ARC} / \mathrm{INFO}$ 软件沿岷江上游干流设立 $5 \mathrm{~km}$ 宽的样带, 每 $5 \mathrm{~km} \times 5 \mathrm{~km}$ 网格为一个样方, 共 68 个 (图 1)。通过空间叠加, 获得每个样方的土地覆盖 信息, 整个样带共包含 12 种土地覆盖类型 (表 1 ), 利用 2001 年 GPS 实地考察数据对分类结果进行精 度评价，准确率达 $65.7 \%$ 。各样方内的土地覆盖因 子值按其所占面积百分比计算, 得到 $68 \times 12$ 的样方 土地覆盖数据矩阵 Ac。

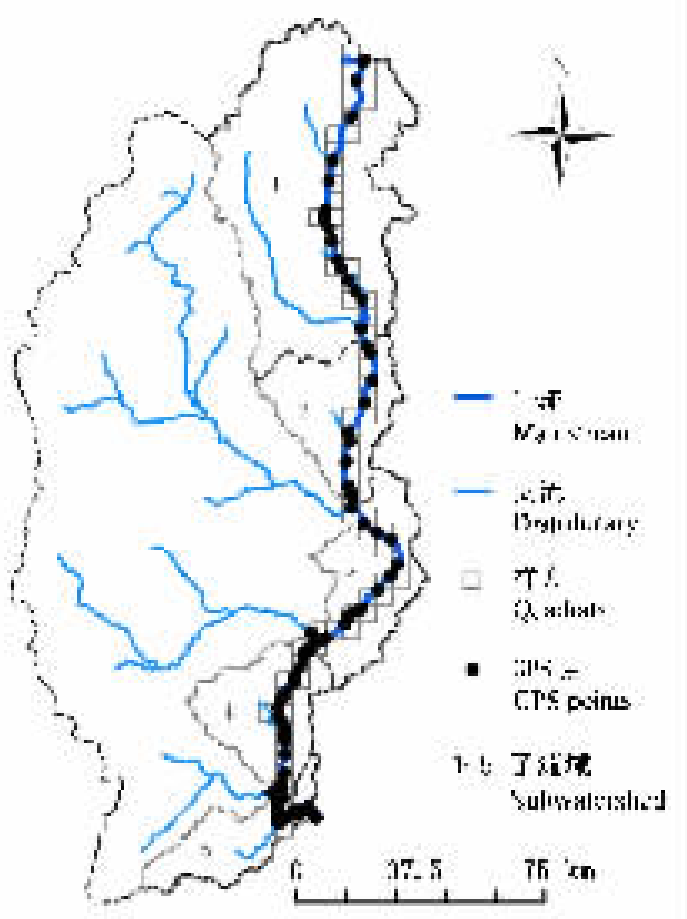

图 1 样方设置及野外调查点

Fig. 1 The quadrats and the GPS points

运用 ARC/INFO 软件 Grid 模块中的空间分析功 能提取各个样方的环境因子，包括地形(样方平均海 拔、坡度), 气象 (样方平均年降水量和年均温),人为
活动影响 (以每平方公里内居民点数目计, 即居民点 密度) 3 方面 5 个因子值, 得到 $68 \times 5$ 的环境矩阵 Ae。

使用 Hill (1979) 设计并由 Minchin 修改的 TWINSPAN 程序(Oksanen \& Minchin , 1997)，对 Ac 进 行双向指示种分析 (Two-way indicator species analysis， TWINSPAN), 完成样方和种类的分类。采用 MVSP 软件包对 Ac、Ae 数据进行除趋势典范对应分析 (Detrended canonical correspondence analysis, DCCA)，以 DCCA 排序图方式显示样方空间排布。DCCA 与 TWINSPAN 分类方法结合, 在 DCCA 排序图上圈定 各个类型的界线，直观看出各类型间的关系，检验 TWINSPAN 分类的合理性, 并用排序轴所含的生态 意义来帮助解释分类结果。

由于河岸带沿河流自上而下的连续及变异，令 各相连接的子流域表现出不同的特征。运用地形数 据，在地理信息系统支持下将怅江干流分为 5 个子 流域，自源头起顺序编号(图 1)。将分类、排序结果 以及各类型土地覆盖特征及环境因子与子流域信息 相叠加, 获得各子流域河岸带特征, 进行综合分析。

表 1 土地覆盖类型编码

Table 1 The code of land cover

\begin{tabular}{clc}
\hline $\begin{array}{c}\text { 编码 } \\
\text { Code }\end{array}$ & \multicolumn{1}{c}{$\begin{array}{c}\text { 类型 } \\
\text { Class name }\end{array}$} & $\begin{array}{c}\text { 比例 }(\%) \\
\text { Percentage }\end{array}$ \\
\hline 11 & 水田 Paddy field & 0.47 \\
12 & 旱地 Dry land & 7.40 \\
21 & 有林地 Woodland & 9.84 \\
22 & 灌木林地 Shrub & 35.19 \\
23 & 其它林地 Other woodland & 3.98 \\
24 & 园地 Orchard & 0.09 \\
31 & 高覆盖度草地 High cover grassland & 10.98 \\
32 & 中覆盖度草地 Moderate cover grassland & 31.46 \\
41 & 河渠 River & 0.10 \\
42 & 湖泊 Lake & 0.12 \\
51 & 城镇用地 Town & 0.14 \\
52 & 工矿用地 Factory & 0.22 \\
\hline
\end{tabular}

\section{2 结果分析}

2.1 对 12 种土地覆盖类型的 TWINSPAN 分类

进行 TWINSPAN 等级分类后，根据土地覆盖类 型的现实意义，选取第二级分类水平，将 12 种土地 覆盖类型划分为 3 个类别组, 分别显示出不同的土 地覆盖特征(图 2)： 
第一组:包括的土地覆盖类型有水田 (11)、旱地 (12)、有林地(21)、高覆盖度草地(31)。从组成上可 以看出, 该类土地覆盖类别组表征了植被覆盖度较 高的类型。农田类型由于人为耕种作用, 其在生长 季期间总能保持较高的植被覆盖度, 虽不属于自然 土地覆盖类型, 但将其划为高植被覆盖度类型仍是 合理的。本类别组占研究区总面积的 $28.69 \%$ 。

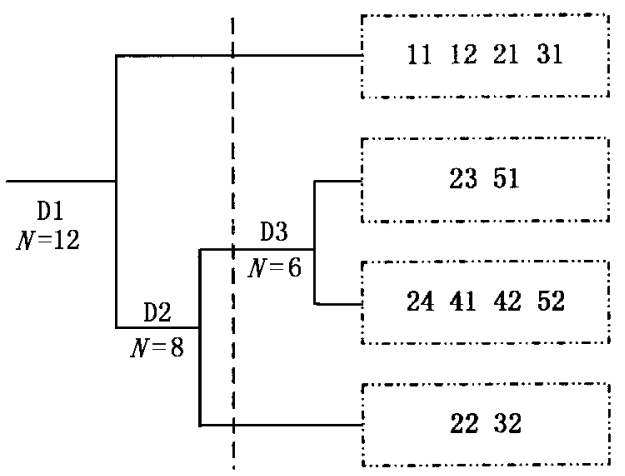

图 212 种土地覆盖类型的 TWINSPAN 分类树状图 Fig. 2 Dendrogram of the TWINSPAN classification of 12 classes of land cover

D1、D2、D3 :1、2、3 级分割 Division 1,2 and 3

第二组 :包括灌木林地 (22)、中覆盖度草地 (32)，反映了植被覆盖程度中等的土地覆盖类别。 本组占研究区总面积的 $66.65 \%$ 。该类别尽管只包 括两种土地覆盖类型, 却占据着广大面积, 是峮江上 游干流沿岸最主要的土地覆盖类别。

第三组 :包括园地(24)、河渠(41)、湖泊(42)、工 矿用地 (52)、其它林地 (23) 以及城镇用地 (51), 该组 中，以低/非植被覆盖类型为主，包括水体和人工建 筑，因此本类别可作为表征人为干扰的一个标志组。 本组占研究区总面积的 $4.65 \%$ 。

以上分类结果呈现出以植被覆盖度为主要区分 标准的分类特征,显示出研究区土地覆盖格局基本 状况:由灌木林地和中覆盖度草地组成的中度植被 覆盖类型占据了研究区内大部分面积, 高植被覆盖 类型次之,低/非植被覆盖类型较少。

各类别组的分布沿河流自上而下, 存在明显差 异(图 3)。作为最大类别的第二组分布曲线呈凸 形，在 2 4 子流域显著占优，而在 $1 、 5$ 比例有所下 降，即流域中段河岸带以中度植被覆盖为主。第一 组则相反, 呈凹形分布, 在 1.5 子流域分布比例高于 河流中段 2 4 子流域, 并仅在源头 1子流域占优 , 即高植被覆盖主要出现在流域源头和下游, 源头的 高覆盖类型以自然植被为主, 而下游以农田为主。
第三组在整个流域内分布比例均较低,在子流域 5 比例稍高，其次为子流域 3 ,即低/非植被覆盖类型 集中出现在 3、5 子流域, 反映出 $3 、 5$ 子流域相对略 强的人为干扰程度。根据以上各类别组的空间分布 特征，河岸带明显分为上、中、下 3 段 :子流域 1 为上 段 植被覆盖率高, 子流域 2 4 为中段, 以中度植被 覆盖率为其显著特征;子流域 5 为下段,低/非植被 覆盖类型偏高,显示一定程度的人为干扰特征。由 此, 可看出河岸带自上而下呈现出自然植被覆盖度 逐渐降低, 人为干扰逐渐加强的梯度变化。

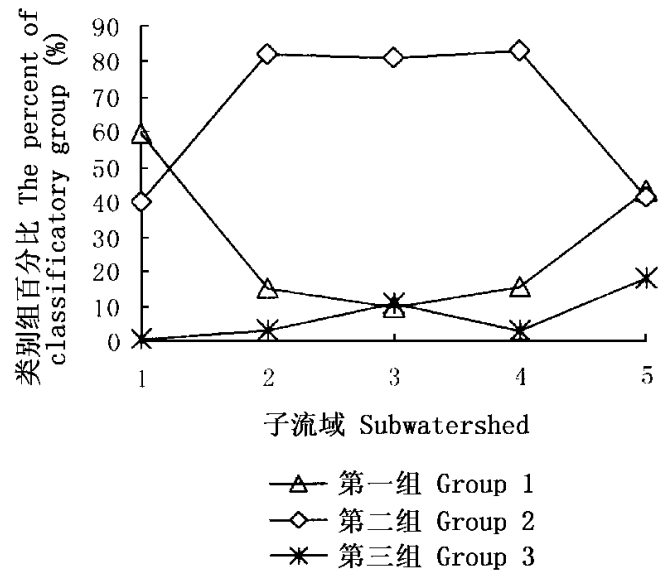

图 3 各子流域中类型组分布比例

Fig.3 The distribution of the classificatory group in subwatersheds

\section{2 对 68 个样方的 TWINSPAN 分类}

对 68 个样方进行 TWINSPAN 等级分类 结合现 实意义 划分为 8 类样方群 (图 4), 每种类群拥有相 似的土地覆盖组成。其空间分布显示各类群内部有 强烈的空间聚集性(图 5), 说明研究区土地覆盖相 似相聚的特性。为体现空间分布特征, 以各类型在 流域中的位置为序 统计各类群的环境因子、组成成 分及所属子流域 (表 2)。与土地覆盖类型的分类结 果一致 样方分类结果亦显示出河岸带上、中、下游 的典型区别。

上游子流域 1 独有 VI、VII、VII 类群，共同特点为 高植被覆盖类别比例高而低/非植被类别所占份额 极小, 海拔高, 降水少, 年均温低, 居民点密度低。其 中各个类群又显示出一定差别和梯度。

河流源头主要分布着类型 VIII,占总面积的 $4.41 \%$ 。中植被覆盖类型近 2 倍于高植被覆盖类 型。受人为干扰最小, 海拔最高, 受海拔影响其水热 条件为整个流域最差, 显示出自然条件对植被覆盖 的影响。 
表 2 样方类型及特征

Table 2 Quadrats classification and characteristic

\begin{tabular}{|c|c|c|c|c|c|c|c|c|}
\hline \multirow[b]{2}{*}{$\begin{array}{l}\text { 类群 } \\
\text { Type }\end{array}$} & \multirow[b]{2}{*}{$\begin{array}{c}\text { 子流域 } \\
\text { Sub- } \\
\text { watershed }\end{array}$} & \multicolumn{3}{|c|}{ 土地覆盖组成 Land cover } & \multicolumn{4}{|c|}{ 环境因子 Environmental factors } \\
\hline & & $\begin{array}{l}\text { 第一组比例 } \\
\text { Percentage of } \\
\text { group } 1(\%)\end{array}$ & $\begin{array}{l}\text { 第二组比例 } \\
\text { Percentage of } \\
\text { group } 2(\%)\end{array}$ & $\begin{array}{l}\text { 第三组比例 } \\
\text { Percentage of } \\
\text { group } 3(\%)\end{array}$ & $\begin{array}{c}\text { 海拔高度 } \\
\text { Elevation } \\
(\mathrm{m})\end{array}$ & $\begin{array}{c}\text { 年降水量 } \\
\text { Annual } \\
\text { precipitation } \\
(\mathrm{mm}) \\
\end{array}$ & $\begin{array}{c}\text { 年均温 } \\
\text { Average annual } \\
\text { temperature } \\
\left({ }^{\circ} \mathrm{C}\right) \\
\end{array}$ & $\begin{array}{c}\text { 居民点密度 } \\
\text { Density of } \\
\text { residence } \\
\left(\mathrm{km}^{-2}\right)\end{array}$ \\
\hline VIII & 1 & 35.10 & 64.88 & 0.02 & 3892.33 & 386.66 & 3.24 & 0.02 \\
\hline VI & 1 & 78.13 & 21.27 & 0.60 & 3169.08 & 656.67 & 5.84 & 0.09 \\
\hline VII & 1 & 48.75 & 51.25 & 0 & 3574.33 & 686.52 & 5.64 & 0.09 \\
\hline III & $2,3,4$ & 3.93 & 95.36 & 0.81 & 2412.19 & 650.63 & 10.74 & 0.12 \\
\hline II & 3,4 & 8.65 & 75.19 & 16.16 & 1856.46 & 793.49 & 11.67 & 0.13 \\
\hline IV & $1,2,3,4$ & 24.58 & 72.11 & 3.31 & 2536.40 & 721.82 & 8.64 & 0.15 \\
\hline V & 5 & 50.89 & 42.02 & 7.09 & 1615.00 & 1161.23 & 15.59 & 0.15 \\
\hline I & 5 & 35.33 & 42.37 & 22.30 & 1061.00 & 1122.02 & 15.30 & 0.21 \\
\hline
\end{tabular}

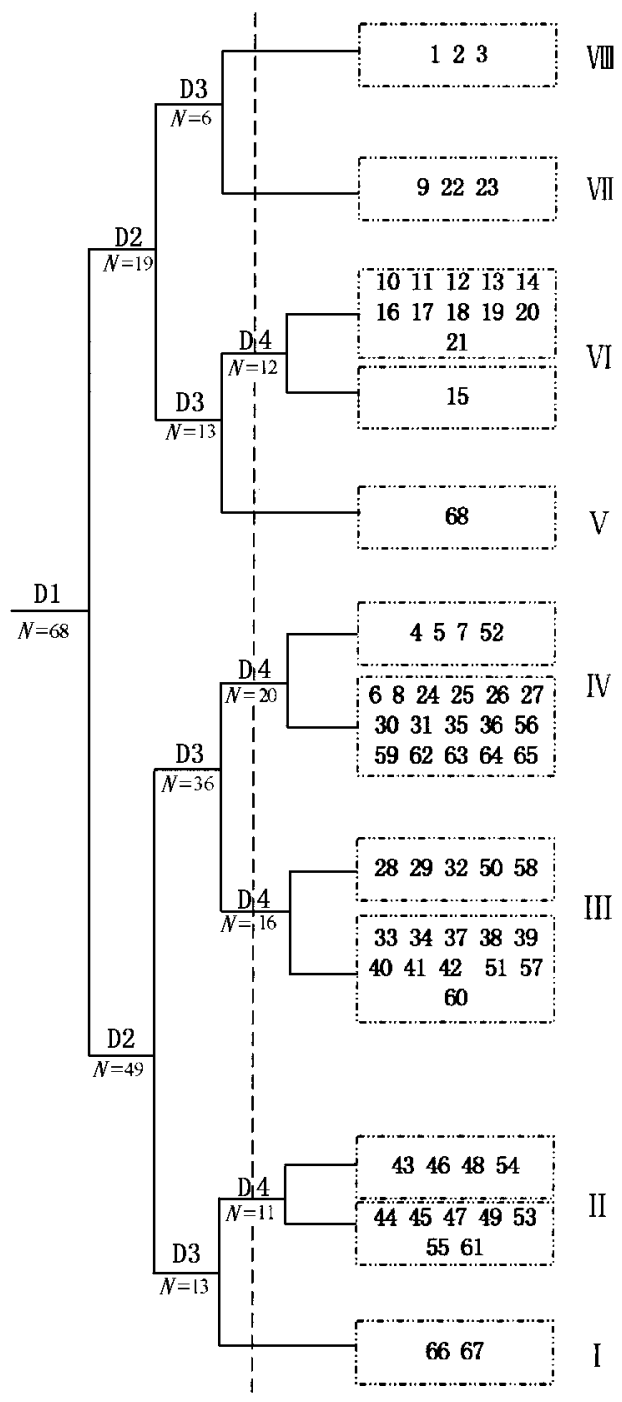

图 468 个样方的 TWINSPAN 分类树状图

Fig.4 Dendrogram of the TWINSPAN classification of 68 quadrats D1、D2、D3、D4 :1、2、3、4 级分割 Division 1,2,3 and 4

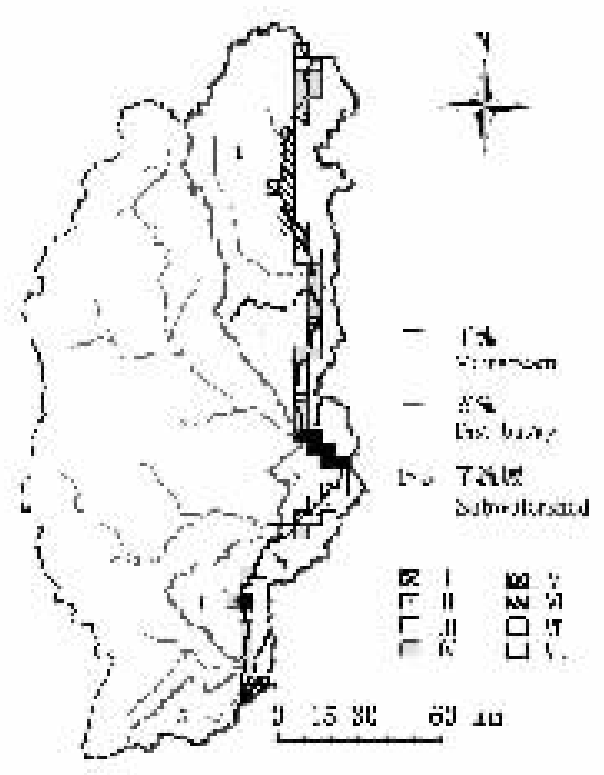

图 5 TWINSPAN 类型地理分布

Fig.5 The geographic distribution of the TWINSPAN types I VIII :8 类样方群 Eight quadrats types

类型 V连续分布于流域上游,占流域总面积的 $17.65 \%$ ，拥有最高比例的高覆盖类型。与类型 VII 相 比,后者高覆盖类减少而中覆盖类增加, 两种类型水 热条件与人为干扰程度相当, 但后者海拔明显升高。 说明在流域上游, 海拔是制约植被覆盖度的重要因 素之一。

流域中段 2４子流域，拥有 II 、III IV 类群，土 地覆盖均以中植被覆盖类型占优, 其自然条件介于 1 , 5 子流域之间。

类型 III :在流域中段2～4子流域均有分布，共 
包含 16 个样方，占总流域面积的 $23.53 \%$;中度植被 覆盖类别所占比例相对最大, 是中度植被覆盖的典 型代表。

类型 II :包含 11 个样方, 占流域总面积的 $16.18 \%$ 集中分布在茂县至汶川间。以中覆盖度植 被占优, 高植被覆盖类型较少, 而低/非植被覆盖类 型相对偏多。从影响因子来看, 年均温相对偏高, 人 为干扰强度中等, 表征了在焚风效应和人为干扰共 同作用下形成的典型半干旱偏湿、干旱河谷的土地 覆盖特征。

类型IV :广泛分布于流域各处, 属于一种中间过 渡类群。所占面积最大, 共包含 20 个样方, 为总面 积的 $29.41 \%$; 以中等植被覆盖类型为主。拥有一 定比例的低/非植被覆盖类型，居民点密度相对偏多 $\left(0.15 \mathrm{~km}^{-2}\right)$ 表现了一定的人为干扰状况下研究区 典型的土地覆盖特征。

下段子流域 5 独有 I、V 类群, 其共同特点是 高、中植被覆盖类型比例大体相当, 低/非植被覆盖 类型比重较大, 高植被覆盖类型主要是农田。从环 境因子来看, 该流域海拔较低, 降水量和年均温较 高, 居民点密度较大。毗邻成都平原, 人类活动历史 悠久, 有很强的人为干扰特征。

类型 $V$ :仅包含 1 个样方，占总面积的 $1.47 \%$; 高植被覆盖度类别约占一半 $(50.89 \%)$, 同时低/非 植被覆盖类型相对较多, 居民点密度也偏大 $(0.15$ $\mathrm{km}^{-2}$ )。该类型拥有研究区内最高的年降水量 (1 $161.23 \mathrm{~mm})$ 和年均温 $\left(15.59^{\circ} \mathrm{C}\right)$, 充足的水热资 源利于植物生长, 同时也适于人类居住, 从原始土地 覆盖图亦可看出, 该区高覆盖度的类型以农田为主， 因此该类主要是一种人为活动造成的土地覆盖类 型。

类型 I :包含 66.67 样方，占总面积的 $2.94 \%$ 。
该类群低/非植被覆盖类别所占比例最高，居名点密 度也最高 $\left(0.21 \mathrm{~km}^{-2}\right)$,所拥有高植被覆盖类别以农 田为主，表征了该类型强烈的人为干扰特性。

综上所述，通过 TWINSPAN 分类得到 8 种样方 群, 各类群所包含的样方土地覆盖特征相似, 空间上 聚集分布。其中, 类型 $I$ 植被覆盖度最高, 类型 III 中 度植被覆盖最多, 类型 I 低/非植被覆盖比重最大， 类型 IV 分布最广, 类型 II 显示出典型的干旱河谷特 征。依据样方群特征及空间分布形态同样可将流域 分为上、中、下 3 段。上段高植被覆盖类型比重较 大, 中段以中植被覆盖类型为主, 下段则表现出人为 干扰特性, 大体呈现自然植被覆盖度逐渐下降, 人工 土地覆盖类型逐渐增多的趋势。土地覆盖类型的梯 度变化是环境因子梯度变化造成的, 沿流域河岸带 自上而下，海拔逐渐下降，年降水量逐渐增加，人为 干扰强度逐渐上升, 年均温在总体逐渐升高的趋势 下在中段干旱河谷区域偏高。

\subsection{DCCA 排序}

DCCA 分析结果显示排序轴能够显著表现土地 覆盖类型和环境因子的相关关系(表 3 ) 绘制样方 的二维排序图 (图 6)。梯度变化规律以第一轴为 主，第二轴次之。

从箭头表示的环境因子来看, 箭头连线最长的 为年均温 (TEM) , 其次为海拔高度 (DEM) ,第三为年 降水 (RAIN), 说明土地覆盖类型的分布与年均温相 关性最大, 其次为海拔高度, 与居民点密度 (RES) 的 相关性最小, 即岷江上游河岸带土地覆盖类型的分 布主要受自然因素制约。箭头连线在排序轴中的斜 率表示环境因子与排序轴相关性的大小, 箭头所处 的象限表示环境因子与排序轴之间相关性的正负关 系。从图中可以看出,第一轴的生态意义是比较 清楚的: 与第一轴相关最大的环境变量是年均温

表 3 DCCA 排序统计表

Table 3 Statistic for the first three axes of DCCA

\begin{tabular}{|c|c|c|c|c|}
\hline & & 轴 1 Axis 1 & 轴 2 Axis 2 & 轴 3 Axis 3 \\
\hline \multirow{5}{*}{$\begin{array}{l}\text { 环境因子-排序轴相关系数 Correlations of environmental vari- } \\
\text { ables with the first three axes of DCCA }\end{array}$} & 海拔高度 DEM & 0.680 & 0.206 & 0.285 \\
\hline & 年均温 TEM & -0.830 & -0.086 & -0.451 \\
\hline & 年降水 RAIN & -0.326 & -0.708 & -0.034 \\
\hline & 居民点密度 RES & 0.171 & -0.632 & -0.276 \\
\hline & 坡度 SLOP & -0.428 & 0.013 & -0.793 \\
\hline \multicolumn{2}{|c|}{ 土地覆盖类型-环境相关系数 Landcover-environment correlation coefficients } & 0.762 & 0.575 & 0.451 \\
\hline \multicolumn{2}{|c|}{ 特征值 Eigenvalues } & 0.258 & 0.074 & 0.023 \\
\hline \multicolumn{2}{|c|}{ 累计解释量 Cumulative percentage variance of landcover-environment relation } & 60.879 & 81.702 & 81.702 \\
\hline
\end{tabular}




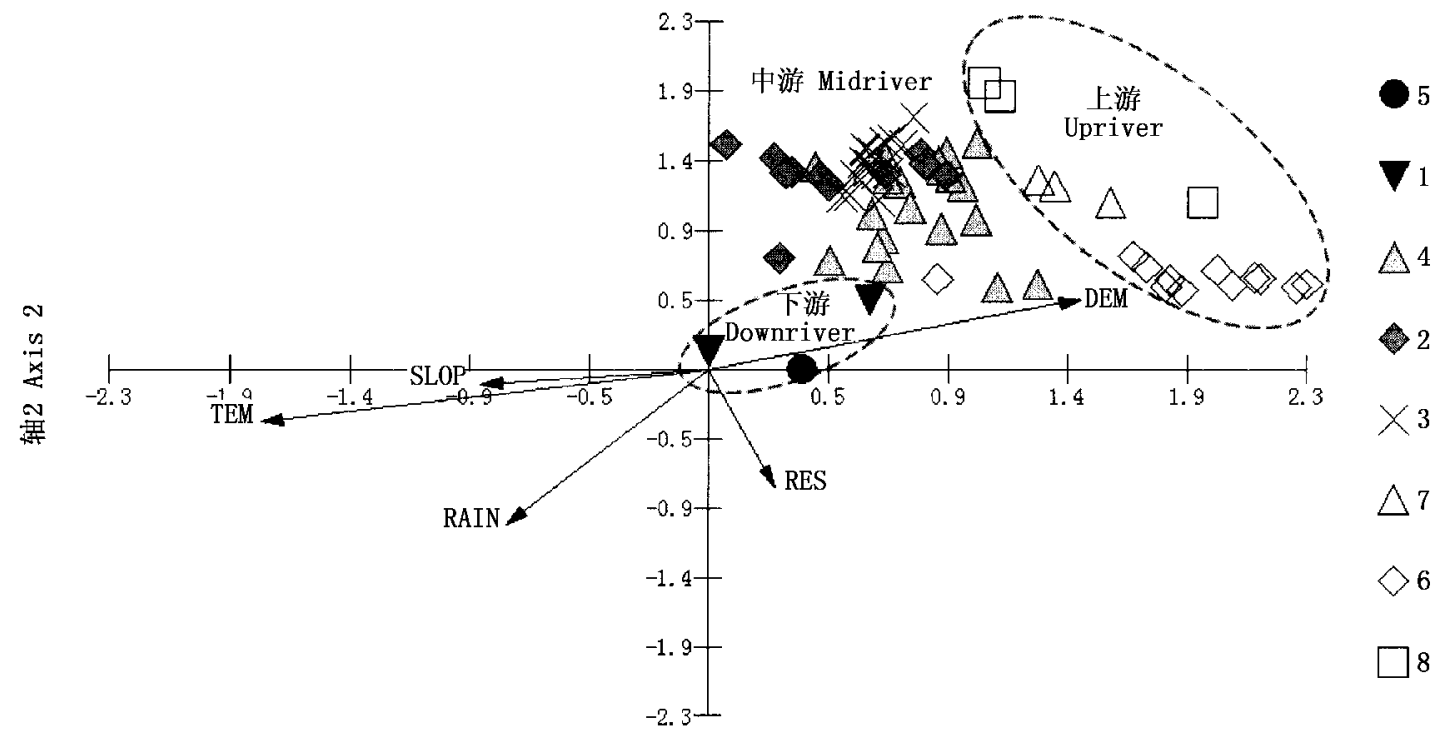

轴1 Axis 1

图 668 个样方的 DCCA 二维排序图

Fig. 6 Two-dimensional DCCA ordination diagram of 68 quadrats DEM、TEM、RAIN、RES、SLOP :见表 3 See Table 3 1 8 : 类型 $1 \sim 8$ Type $1-8$

(TEM) (相关系数为 -0.830$)$, 其次是海拔 (DEM) (相关系数为 0.680 ), 即沿 DCCA 第一轴从左到右, 年均温逐渐下降, 海拔逐渐升高。第一轴解释了土 地覆盖-环境因子相关性的 $60.9 \%$ 。第二轴则主要 体现了年降水量 (RAIN) 的变化 (相关系数为 $-0.708)$,即沿第二轴从下向上, 年降水量逐渐降 低。此外, 第二轴还显示了居民点密度 (RES) 变化 (相关系数为 -0.632 ), 从下而上人类干扰程度逐渐 减弱。第一、二轴共解释了土地覆盖-环境因子相关 性的 $81.7 \%$,代表了最主要的影响因素。第三轴主 要体现了坡度(SLOP)变化(相关系数 -0.793 )。

从样方分布格局来看, 根据 TWINSPAN 分类所 得的 8 个样方类群在排序图上有各自明确的分布范 围和界限, 证实了 TWINSPAN 结果的可靠性。分属 于流域上、中、下 3 段的各类群分布集中, 各段间存 在较为明确的界限, 刻画出流域河岸带自上而下呈 现出的总体梯度格局。总体趋势是温度升高、海拔 下降、降水增加。同时可以看到，上、下游的分布相 对集中，而中游较为离散，类型 II 特殊的分布位置是 造成这一现象的主要原因。类型 II 不遵循流域自上 而下的总体趋势, 其在第一轴的分布较中游其它类 型低, 与上游相似, 但第二轴分布位置较上游高。从 TWINSPAN 分类已知类型 II 是干旱河谷类型, 结合 排序轴的生态意义，可知该类型与相同温度下其它 类型相比降水偏少 相应的, 比相同降水量下其它类
型温度高，这种水热条件的不匹配使其拥有独特的 土地覆盖特征。

综合分析可知, 岷江上游河岸带土地覆盖类型 主要受以温度和海拔为主的自然因素影响, 形成上、 中、下 3 段各具特色的河岸带景观。顺流而下总体 来说气温逐渐升高, 海拔逐渐降低。同时, 降水逐渐 增加，人为干扰程度逐渐变大，它们也对河岸带土地 覆盖格局产生影响。水热条件的独特性造就了茂县 至汶川的半干旱偏湿干旱河谷。

\section{3 结论与讨论}

利用 TWINSPAN、DCCA 方法 结合空间信息，对 岷江上游干流河岸带土地覆盖格局进行了分析, 得 到如下结论 :

1)土地覆盖可分为 3 种类别:高植被覆盖、中植 被覆盖及低/非植被覆盖。由灌木林和中覆盖度草 地组成的中度植被覆盖是研究区最主要的类型, 高 度植被覆盖在子流域 1.5 比例稍大，子流域 1 高覆 盖类型主要为自然植被, 而在子流域 5 主要为农田。 低/非自然植被主要集中于子流域 3、5。

2)样方可分为 8 个类群，它们拥有相似的土地 覆盖组成, 同种类群常沿河岸带相互聚集。

3)根据土地覆盖特征, 河岸带可分为上、中、下 3 段，分别包括子流域 1、子流域 2４，子流域 5。流 域上段河岸带植被覆盖度较高；中段占总面积最大， 
以中度植被覆盖类型为主;下段集中了大部分人工 土地覆盖类型。顺流而下自然植被覆盖度逐渐下 降, 人工地覆盖类型逐渐增多。

4) 气温、海拔是影响怅江上游干流河岸带土地 覆盖格局的最重要因素, 此外降水和人类活动对其 也有影响。除干旱河谷区, 顺流而下,总体而言海拔 逐渐降低, 水热条件逐渐改善, 同时人类干扰强度也 逐渐增加, 造成流域 3 段截然不同的土地覆盖格局。

5)茂县至汶川的半干旱偏湿干旱河谷能够被成 功识别，水、热条件的共同作用造就了该特殊类型。 相关研究也表明, 蒸发旺盛是该区干旱河谷的主要 成因 (吴勇等，2003)。

作为一种有益的尝试，本研究使用了植被分类、 排序方法来研究土地覆盖格局, 但尚存在很多问题 :

1)缺乏对结果的检验, 尤其是实证研究, 应在今 后的研究中予以补充。

2)景观尺度的研究毕竟不同于群落植被研究， 空间尺度扩大后随之产生的空间属性成为研究中不 可回避的问题, 这使得我们在分析分类、排序结果时 必须考虑其空间位置、分布以及整个景观的空间异 质性。而从本研究实例来看, 与空间信息的结合也 使得分类、排序的结果更具生态学意义。因此, 我们 建议将植被数量方法适当引入景观尺度的研究中 时, 应以统计手段加上景观生态学的空间视野来解 释大尺度上的生态问题。

\section{参 考 文 献}

Aguiar FC, Ferreira MT (2005). Human-disturbed landscapes: effects on composition and integrity of riparian woody vegetation in the Tagus River basin, Portugal. Environmental Conservation, $32,30-41$.

Chen JQ (陈吉泉) (1996). Riparian vegetation characteristics and their functions in ecosystems and landscapes. Chinese Journal of Applied Ecology (应用生态学报)，7, 439-448.

Corbacho C, Sanchez JM, Costillo E (2003). Patterns of structural complexity and human disturbance of riparian vegetation in agricultural landscapes of a Mediterranean area. Agriculture Ecosystems \& Environment, 95, 495 - 507.

Deng HB (邓红兵), Wang QL (王庆礼), Cai QH (蔡庆华) (1998). Watershed ecology-new discipline, new idea and new approach. Chinese Journal of Applied Ecology (应用生态学 报), 9, 443-449. (in Chinese with English abstract)

Elderd BD (2003). The impact of changing flow regimes on riparian vegetation and the riparian species Mimulus guttatus. Ecological Applications, 13, 1610 - 1625 .

Fleishman E, Mcdonal N, Mac Nally R, Murphy DD, Walters J, Floyd T (2003). Effects of floristics, physiognomy and non-na- tive vegetation on riparian bird communities in a Mojave Desert watershed. Journal of Animal Ecology, 72, 484-490.

Guo JH (郭敬辉), Wang YZ (王玉枝), Li XY (李秀云) (1985). Hydrography at West of Sichuan and North of Yunnan (川西滇北地区水文地理). Science Press, Beijing. (in Chinese)

Heartsill-Scalley T, Aide TM (2003). Riparian vegetation and stream condition in a tropical agriculture-secondary forest mosaic. Ecological Applications, 13, 225 - 234 .

Hill MO (1979). TWINSPAN-a FORTRAN Program for Arranging Multivariate Data in an Ordered Two-Way Table by Classification of the Individuals and Attributes. Cornell University, Ithaca, NY. Lamb EG, Mallik AU, Mackereth RW (2003). The early impact of adjacent clearcutting and forest fire on riparian zone vegetation in northwestern Ontario. Forest Ecology and Management, 177, $529-538$.

$\mathrm{Li} \mathrm{AN}$ (李爱农), Zhou WC (周万村), Li FB (李发斌), Ma ZZ (马泽忠) (2005). An analysis on spatial distribution pattern of land use in upper reaches of Minjiang River based on spatial technology. Journal of Arid Land Resources and Environment (干 旱区资源与环境)，19(6), 53-57. (in Chinese with English abstract)

Li CW (李崇巍), Liu SR (刘世荣), Sun PS (孙鹏森), Ge JP (葛剑平) (2005). Analysis on landscape pattern and eco-hydrological characteristics at the upstream of Minjiang River. Acta Ecologica Sinica (生态学报), 25,691-698. (in Chinese with English abstract)

Liu LJ (刘丽娟) (2004). Study on Vegetation Pattern, Vegetation Dynamics and Its Influence on Hydrological Process in the Upper Minjiang River (岷江上游植被格局、动态及其生态水文功 能研究). PhD dissertation, College of Life Science, Beijing Normal University, Beijing, 45 - 55. (in Chinese with English abstract)

Liu LJ (刘丽娟), Zan GS (各国盛), Ge JP (葛剑平), Bi XL (毕晓丽), Zhou R(周睿) (2005). Application of MTCLIM in climate modeling for the up-reaches of Minjiang River. Resources and Environment in the Yangze Basin (长江流域资源与环境), 14, 248 - 253. (in Chinese with English abstract)

Lyon J, Sagers CL (2003) . Correspondence analysis of functional groups in a riparian landscape. Plant Ecology, 164, 171 - 183. Malanson GP (1993). Riparian Landscape. Cambridge University Press, Cambridge.

Medina-Vogel G, Kaufman VS, Monsalve R, Gomez V (2003). The influence of riparian vegetation, woody debris, stream morphology and human activity on the use of rivers by southern river otters in Lontra provocax in Chile. Oryx, 37, 422-430.

Naiman RJ, Decamps H (1997). The ecology of interfaces: riparian zones. Annual Review of Ecology and Systematics, 28, 621 658 .

Oksanen J, Minchin PR (1997). Instability of ordination results under changes in input data order: explanations and remedies. 
Journal of Vegetation Science, 8, 447 - 454 .

Schwabe A (1989). Vegetation complexes of flowing water habitats and their importance for the differentiation of landscape units. Landscape Ecology, 2, 237 - 253 .

Song YC (宋永昌) (2001). Vegetation Ecology（植被生态学）. East China Normal University Press, Shanghai. (in Chinese)

Tabacchi E, Planty-Tabacchi AM (2003) . Recent changes in riparian vegetation: possible consequences on dead wood processing along rivers. River Research and Applications, 19, 251 - 263.

Vannote RL, Minshall GW, Cummins KW (1980). The river continuum concept. Canadian Journal of Fisheries and Aquatic Sciences, 37, $130-137$.

Wu Y (吴勇), Su ZX (苏智先), Fang JY (方精云)（2003）. Study on causes and ecological renewal of arid and warm valley of upper Minjiang River. Journal of China West Normal University (Natural Science)（西华师范大学学报 (自然科学版) ), 24, 276 - 281. (in Chinese with English abstract)
Yeakley JA, Coleman DC, Haines BL, Kloeppel BD, Meyer JL, Swank WT, Argo BW, Deal JM, Taylor SF (2003). Hillslope nutrient dynamics following upland riparian vegetation disturbance. Ecosystems, 6, $154-167$.

Zhang F (张峰), Zhang JT (张金屯) (2000). Research progress of numerical classification and ordination of vegetation in China. Journal of Shanxi University (Natural Science Edition) (山西大 学学报 (自然科学版)), 23,278-282. (in Chinese with English abstract)

Zhang JT (张金屯) (2004)。 Quantitative Ecology (数量生态 学), Science Press, Beijing. (in Chinese)

Zhang RZ (张荣祖) (1992). The Arid Valleys of the Hengduan Mountains Region (横断山区干旱河谷). Science Press, Beijing. (in Chinese)

Zhao YH, He XY, Hu YM, Chang Y (2005). Landscape pattern change in the upper valley of Min River. Journal of Forestry Research, 16, $31-34$. 